\author{
J.-P. BESSON ${ }^{1, \infty}$ \\ S. SCHILT ${ }^{1}$ \\ E. ROCHAT ${ }^{2}$ \\ L. THÉVENAZ ${ }^{1}$
}

\title{
Ammonia trace measurements at ppb level based on near-IR photoacoustic spectroscopy
}

\author{
${ }^{1}$ Ecole Polytechnique Fédérale de Lausanne (EPFL), Nanophotonics and Metrology Laboratory, \\ 1015 Lausanne, Switzerland \\ 2 Omnisens SA, Riond-Bosson 3, 1110 Morges, Switzerland
}

\begin{abstract}
Received: 18 April 2006/Revised version: 17 May 2006 C) Springer-Verlag 2006

ABSTRACT A photoacoustic sensor using a laser diode emitting near $1532 \mathrm{~nm}$ in combination with an erbium-doped fibre amplifier has been developed for ammonia trace gas analysis at atmospheric pressure. $\mathrm{NH}_{3}$ concentration measurements down to $6 \mathrm{ppb}$ and a noise-equivalent detection limit below $3 \mathrm{ppb}$ in dry air are demonstrated. Two wavelength-modulation schemes with $1 f$ and $2 f$ detection using a lock-in amplifier were investigated and compared to maximise the signal-to-noise ratio. A quantitative analysis of $\mathrm{CO}_{2}$ and $\mathrm{H}_{2} \mathrm{O}$ interference with $\mathrm{NH}_{3}$ is presented. Typical concentrations present in ambient air of $400 \mathrm{ppm} \mathrm{CO}_{2}$ and $1.15 \% \mathrm{H}_{2} \mathrm{O}\left(50 \%\right.$ relative humidity at $\left.20^{\circ} \mathrm{C}\right)$ result in a $\mathrm{NH}_{3}$ equivalent concentration of $36 \mathrm{ppb}$ and $100 \mathrm{ppb}$, respectively.
\end{abstract}

PACS 42.62.Fi; 43.35.Ud; 42.55.Px

\section{$1 \quad$ Introduction}

Sensitive and continuous ammonia $\left(\mathrm{NH}_{3}\right)$ monitoring is relevant in various applications, such as $\mathrm{DeNO}_{x}$ processes widely used in power plants and incinerators to reduce $\mathrm{NO}_{x}$ emissions [1], process control in the semiconductor industry, where extremely low levels of $\mathrm{NH}_{3}$ in clean rooms may drastically deteriorate the performances of the lithography process [2], environment monitoring to quantify $\mathrm{NH}_{3}$ emissions from animal production facilities and automobile traffic $[3,4]$, or in medicine to analyse breath $\mathrm{NH}_{3}$ levels as a diagnostic tool [5]. Whereas detection limits in the partsper-million (ppm) or sub-ppm range are sufficient for some of these applications (i.e., DeNO $x$ process), most of them require much better performances at parts-per-billions (ppb) level.

Laser photoacoustic spectroscopy (PAS) is a widely recognised method for its excellent performance in trace gas measurements from ppm down to ppb levels. This technique provides many advantages such as high selectivity and sensitivity, on-line, real time and contactless measurements in a compact experimental arrangement. Since the sensitivity of this technique scales with optical power, high power lasers are generally required for high sensitivity. Semiconductor distributed feedback lasers emit typical powers of several tens

Fax: +41-21-693 2614, E-mail: jean-philippe.besson@epfl.ch of milliwatts enabling sensitivities in the sub-ppm range for many species $[6,7]$, including ammonia [8]. Better detection limits down to $\mathrm{ppb}$ level require higher output power generally achieved using gas lasers ( $\mathrm{CO}$ and $\mathrm{CO}_{2}$ lasers). However, the use of fibre amplifiers combined with standard telecom diode lasers is an attractive alternative to these cumbersome gas lasers to improve the detection limits towards ppb levels. The first use of an erbium-doped fibre amplifier (EDFA) in combination with PAS was reported by Webber et al. in 2003 for $\mathrm{NH}_{3}$ detection [9]. Even if these authors reported a detection limit of a few ppb of $\mathrm{NH}_{3}$, this was extrapolated from higher concentration and no real measurement below $100 \mathrm{ppb}$ is shown. Monitoring ammonia at sub-ppm level is a challenging task due to the sticky nature of this polar molecule and the related adsorption-desorption problems [10,11]. The work reported here aims at presenting ammonia measurements at atmospheric pressure down to a concentration of a few ppb in dry air ( $80 \%$ nitrogen, $20 \%$ oxygen) and at evaluating carbon dioxide $\left(\mathrm{CO}_{2}\right)$ and water vapour $\left(\mathrm{H}_{2} \mathrm{O}\right)$ interferences in typical atmospheric conditions.

\section{$2 \quad$ Sensor design}

The photoacoustic (PA) sensor is based on resonant PAS in combination with a laser diode emitting near $1532 \mathrm{~nm}$. The PA cell consists of three acoustic resonators, offering the possibility of measuring up to three gases simultaneously using three lasers (Fig. 1). For $\mathrm{NH}_{3}$ measurements, only one resonator with the corresponding laser diode was used, whereas the two other lasers were not connected. The resonator oscillates in its first longitudinal mode at a frequency of $970 \mathrm{~Hz}$ in air. A quality factor $Q$ of 20 was obtained in this condition. The PA signal was generated by wavelengthmodulation of the laser through a modulation of the injection current. It was detected using a sensitive electret microphone placed in the centre of the resonant cavity where the maximum of the acoustic wave occurs. The PA signal was amplified and measured using a lock-in amplifier with a time constant usually set to $10 \mathrm{~s}$. The PA signals were demodulated at the modulation frequency ( $1 f$ detection) or at twice the modulation frequency ( $2 f$ detection) [12]. These two techniques were investigated and compared to determine the optimal configuration to achieve the minimum detection limit (see Sect. 3.1). 


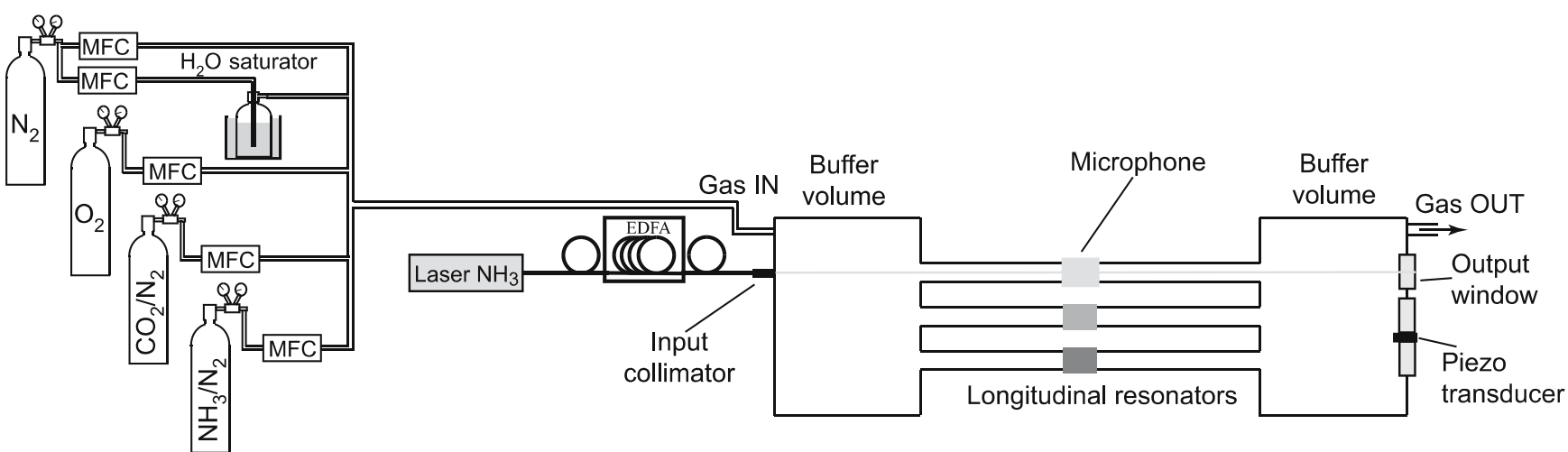

FIGURE 1 Scheme of the experimental set-up including the PA sensor, the erbium-doped fibre amplifier and the gas handling system. Current-modulated light from the DFB laser is amplified and launched into the resonator through a fibre collimator. Mass-flow controllers (MFC) are used to prepare varying low concentrations of $\mathrm{NH}_{3}$ in dry air $\left(80 \% \mathrm{~N}_{2}-20 \% \mathrm{O}_{2}\right) \cdot \mathrm{CO}_{2}$ and water vapour (generated by a $\mathrm{N}_{2}$ flow through a $\mathrm{H}_{2} \mathrm{O}$ saturator) can be added to the mixture to study the interference of these species

The pigtailed DFB laser connected to a fibered collimator is directly mounted on the outer flange of the cell and is aligned along the axis of the resonator. The diode laser is operated in wavelength-modulation mode at either the frequency of the first longitudinal mode of the PA cell ( $1 f$ demodulation) or at half of the PA cell's resonant frequency ( $2 f$ demodulation). The temperature- and current-tuning coefficients are $-13.9 \mathrm{GHz} /{ }^{\circ} \mathrm{C}$ and $-0.85 \mathrm{GHz} / \mathrm{mA}$. This fibered configuration allows an easy insertion of the EDFA to boost the optical power launched into the PA cell. The optical amplifier was operated in the saturation regime and delivered about $750 \mathrm{~mW}$ of amplified power at $1531.67 \mathrm{~nm}$ from the $18.5 \mathrm{~mW}$ laser, thus providing a $16 \mathrm{~dB}$ gain to the laser optical power. The total power of the EDFA including spontaneous emission was about $1 \mathrm{~W}$. Additional details on the sensor can be found in $[7,13]$.

The gas handling system was composed of a certified mixture containing $100 \mathrm{ppm}$ of $\mathrm{NH}_{3}$ buffered in nitrogen $\left(\mathrm{N}_{2}\right)$. $\mathrm{N}_{2}$ and oxygen $\left(\mathrm{O}_{2}\right)$ cylinders were used for dilution and a certified mixture of $5000 \mathrm{ppm}$ of $\mathrm{CO}_{2}$ was used for quantitative interference measurements. $\mathrm{H}_{2} \mathrm{O}$ interference was also investigated by passing part of the flow through a saturator which consists in a water-filled glass cuvette placed in a thermostat bath (see Fig. 1). The flow exiting the cuvette was saturated in water vapour and the humidity was only dependent on the bath temperature. Dilutions were obtained with massflow controllers with a total flow of $1000 \mathrm{sccm}$ (standard cubic centimetre per minute) in the PA cell. This flow reduces the adsorption-desorption process of ammonia in the PA cell and ensures a fast response time of the sensor without adding any extra acoustic noise. However, low $\mathrm{NH}_{3}$ concentrations obtained with mass-flow controllers are approximative because of the adsorption-desorption processes.

The actual $\mathrm{NH}_{3}$ concentrations in the gas stream after the gas mixing system and ahead of the PA cell are measured with an Omnisens TGA300Series trace gas analyzer. The analyzer is based on resonant PAS in combination with a high power $\mathrm{CO}_{2}$ laser. Calibration of the instrument has been validated by using continuous gas generator, based on the dynamic evaporation of an aqueous ammonia solution into a continuous $\mathrm{N}_{2}$ gas stream while being cross-checked with the impinger method (ion chromatography) [14]. The analyzer fea- tures online measurements at relatively high flow rates of up to $5 \mathrm{l} / \mathrm{min}$ and short response times. Its wide measurement range $(0.1 \mathrm{ppb}-6 \mathrm{ppm})$ and linearity of $r^{2}>0.9998$ over the measurement range, low detection limit $(0.1 \mathrm{ppb})$ and demonstrated accuracy $(0.25 \mathrm{ppb}$ or $1 \%)$ makes this analyzer a reference ammonia sensor in the industry and is being used for contamination monitoring in the semiconductor industry and for atmospheric pollution and air quality monitoring applications [14]. The analyser calibration accuracy together with its measurement linearity and range enables precise measurements even at low ppb level and was used throughout the tests as a reference.

\section{$3 \quad$ Results and discussion \\ 3.1 Performance of the sensor}

In order to quantify adsorption-desorption processes in the system, the sensor response time was investigated. The response time of the sensor was first measured at high ammonia concentration (at ppm level) and then in the ppb range. A concentration step from $1 \mathrm{ppm}$ down to $0.5 \mathrm{ppm}$ at $1000 \mathrm{sccm}$ was applied to the sensor and an exponential fit was used to precisely determine the time decay constant. By considering $95 \%$ of gas renewal $\left(1-1 / \mathrm{e}^{3}\right)$, the response time was equal to $95 \mathrm{~s}$. The same process was then applied at low concentration (step from $40 \mathrm{ppb}$ to $20 \mathrm{ppb} \mathrm{NH}_{3}$ ) and a response time of about 6 min was obtained. This decay time was compared with the TGA reference instrument and was found to be $85 \mathrm{~s}$. The difference between the two instruments is principally due to the quality of the coating deposited on the inner surface of the PA cell. In addition, the coating deposition inside the resonators and in a short $6 \mathrm{~mm}$ stainless steel tube at the inlet of the PA cell could not be properly applied for technical reasons.

Two modulation schemes were investigated in order to achieve the best minimum detectable concentration. Firstly, wavelength-modulation mode with first-harmonic detection ( $1 f$ detection) was investigated. This modulation scheme yields to a PA signal which is proportional to the first derivative of the absorption feature. The principal drawback of $1 f$ detection is the presence of either window or wall noise which contributes to the PA signal [15]. Window and wall noise are 
due to the residual intensity modulation (IM) associated with wavelength-modulation when the laser current is modulated. The use of an EDFA in the saturation regime reduced the IM index from the laser by almost a factor 10 (Fig. 2), but a residual noise level was still present.

The modulation amplitude was first optimised to maximise the PA signal. However, this configuration was not optimal due to the high noise level associated to the residual IM. The modulation amplitude was therefore rather chosen to maximise the signal-to-noise ratio instead of the PA signal amplitude. In this case, the current modulation amplitude applied to the laser was $6 \mathrm{~mA}$ corresponding to $1 / 4$ of the amplitude used to maximise the PA signal.

The detection limit of the PA sensor was determined by measuring $\mathrm{NH}_{3}$ dilutions in dry air $\left(80 \% \mathrm{~N}_{2}, 20 \% \mathrm{O}_{2}\right)$ from $150 \mathrm{ppb}$ down to $6 \mathrm{ppb}$ and by measuring the noise level. Ammonia concentrations were precisely monitored with the commercially available trace gas analyser (TGA) provided by Omnisens $\mathrm{SA}$. $\mathrm{NH}_{3}$ concentrations obtained from massflow controllers differed as much as $30 \%$ in comparison with the TGA value (see Table 1), thus proving the importance of a properly calibrated instrument.

Experimental results obtained with $1 f$ detection with respect to $\mathrm{NH}_{3}$ concentration are shown in Fig. 3. The minimum detectable concentration is given by the crossing point between the linear fit and the noise level. In the present configuration, the noise level is as high as $20 \mu \mathrm{V}$ (due to wall or window noise), which is about five times higher than the microphone noise level. A concentration of $6 \mathrm{ppb} \mathrm{NH}_{3}$ passed
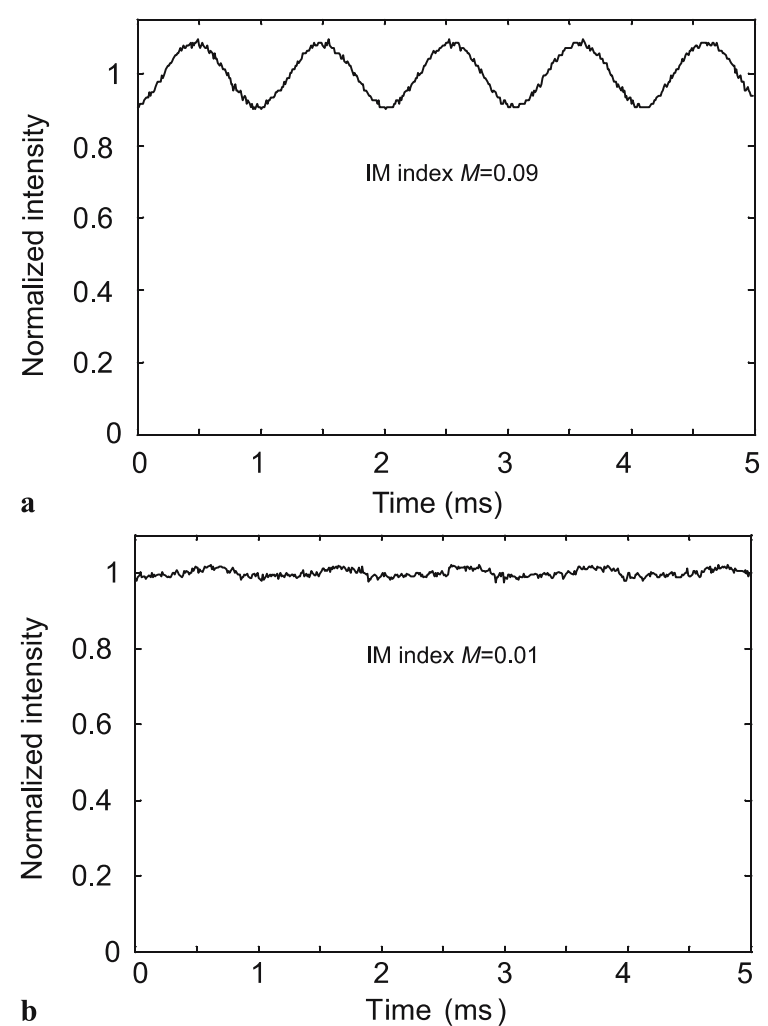

FIGURE 2 Residual intensity modulation of the DFB laser (a) and with the EDFA operated in the saturation regime (b). The signals are normalised to the $\mathrm{dc}$ value and the laser modulation frequency is $1 \mathrm{kHz}$

\begin{tabular}{lcc}
\hline $\begin{array}{l}\text { MFC's } \mathrm{NH}_{3} \\
\text { concentrations (ppb) }\end{array}$ & $\begin{array}{c}\text { TGA's NH} \\
\text { concentrations (ppb) }\end{array}$ & Error (\%) \\
\hline 100 & 92 & 8 \\
50 & 44 & 12 \\
25 & 25 & 0 \\
12.5 & 17 & 36 \\
10 & 12 & 20 \\
5 & 6.5 & 30 \\
\hline
\end{tabular}

TABLE 1 Comparison of $\mathrm{NH}_{3}$ concentrations calculated from mass-flow controllers (MFC) adjustment and measured with Omnisens' trace gas analyser (TGA)

into the sensor could not be detected. Thus, in this configuration, the noise-equivalent detection limit is around $12 \mathrm{ppb}$.

The detection limit may be significantly improved by reducing the noise down to the level of the microphone noise. Since wall noise and window noise result from the residual IM, they mainly occur at the laser modulation frequency and have negligible contribution at higher harmonics. Therefore, a second-harmonic $(2 f)$ detection scheme was applied to improve the sensor performances. For this purpose, a sinusoidal waveform modulation was applied to the laser at half the resonance frequency. The modulation depth was optimised to maximise the PA signal for $\mathrm{NH}_{3}$ detection. Results are presented in Fig. 4, which shows the dependance of the PA signal as a function of the modulation depth for $\mathrm{NH}_{3}$ and $\mathrm{CO}_{2}$. An optimal value of $20 \mathrm{~mA}$ was obtained. The PA signal demodulated at the resonance frequency $(2 f)$ looks like a secondderivative of the absorption feature.

Results obtained with $2 f$ detection with respect to $\mathrm{NH}_{3}$ concentration are presented in Fig. 5. High concentrations starting from $90 \mathrm{ppb}$ were diluted to achieve low concentrations down to nearly 6 ppb. 6 ppb was the lowest concentration achievable with the available mass-flow controllers. Unfortunately, a residual level of a few ppb of ammonia (dot-dashed line in Fig. 5) was very difficult to wash out from the cell and the gas line due to the sticky nature of $\mathrm{NH}_{3}$ and thus contributed to low PA signals. In that case, the sensitivity of the sensor seemed to be limited by this residual level. However,

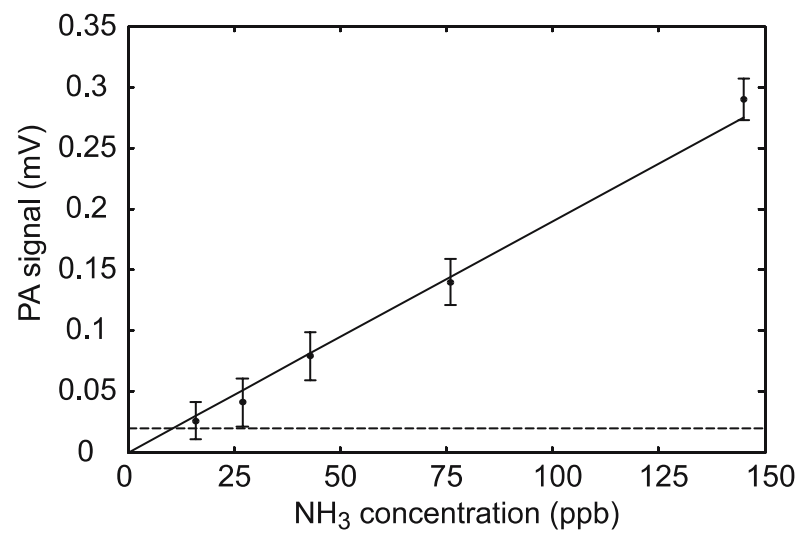

FIGURE 3 PA signal demodulated at $1 f$ as a function of ammonia concentration. Error bars shown on the plot correspond to one standard deviation of the PA signal recorded in a 5-min period with an integration time of $10 \mathrm{~s}$. The line is the result of a linear fit. The dashed line is the noise level obtained by the average over $5 \mathrm{~min}$ of the PA signal recorded with $\mathrm{N}_{2}$ purge. The noise-equivalent detection limit is about $12 \mathrm{ppb}$ 


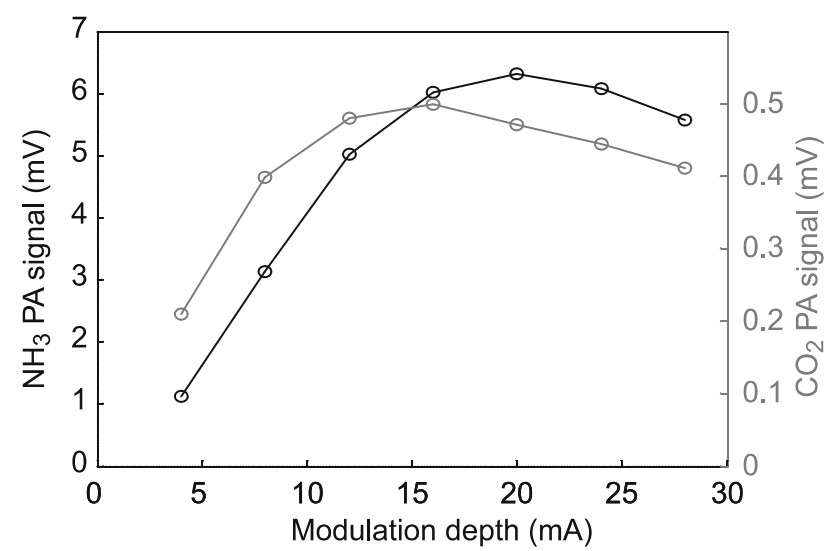

FIGURE 4 Amplitude of the $\mathrm{NH}_{3}$ and $\mathrm{CO}_{2}$ PA signals as a function of the laser current modulation depth in the case of a sinusoidal waveform with $2 f$ detection. An optimal modulation depth of $20 \mathrm{~mA}$ is determined for the detection of ammonia

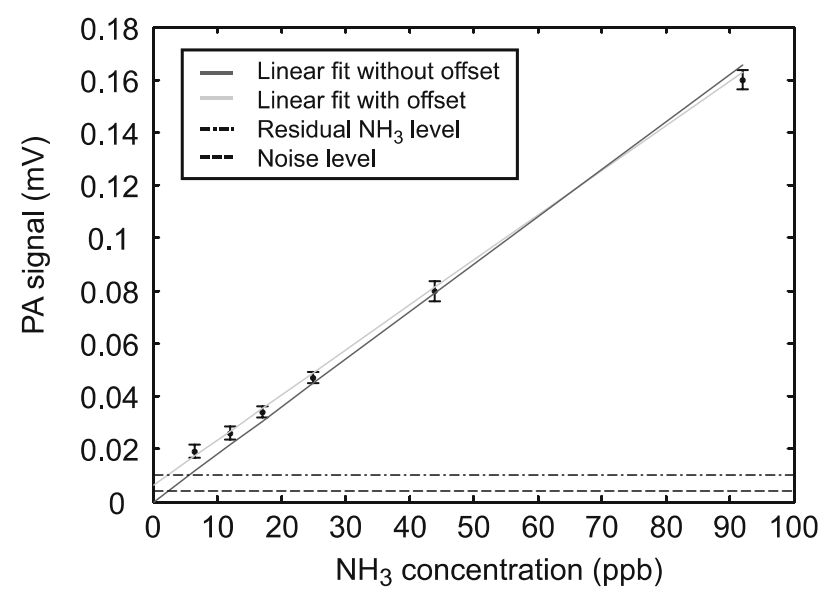

FIGURE 5 PA signal demodulated at $2 f$ as a function of ammonia concentration. Error bars shown on the plot correspond to standard deviation of the PA signal recorded in a 5-min period with an integration time of $10 \mathrm{~s}$. The solid lines are the result of linear fits. The dot-dashed line corresponds to the residual level obtained with a $\mathrm{N}_{2}$ purge. The dashed line is the system noise level (average over $5 \mathrm{~min}, 10 \mathrm{~s}$ integration) observed after an intensive purge of the sensor with high $\mathrm{N}_{2}$ flow saturated with water vapour. The noise-equivalent detection limit is $2.4 \mathrm{ppb}$

by carefully purging the PA cell during one night with a high air flow saturated with water vapour, the sensor was properly cleaned and the residual level was reduced to the noise of the microphone integrated over $10 \mathrm{~s}$ (dashed line in Fig. 5). This configuration yields to a noise-equivalent detection limit of $2.4 \mathrm{ppb}$, thus improving the sensitivity by a factor five compared to $1 f$ detection.

\section{2 $\mathrm{CO}_{2}$ and $\mathrm{H}_{2} \mathrm{O}$ interference with $\mathrm{NH}_{3}$}

In order to identify $\mathrm{H}_{2} \mathrm{O}$ and $\mathrm{CO}_{2}$ interferences with $\mathrm{NH}_{3}$, a PA spectrum of these compounds was measured at atmospheric pressure using the EDFA and an external chopper for the modulation of the incident laser beam (Fig. 6b). For this measurement, a mechanical chopper has been preferred to the direct modulation of the laser injection current in order to produce pure IM. In such conditions, the generated PA spectrum is proportional to the gas absorption coefficient, which makes easier the comparison between ex-
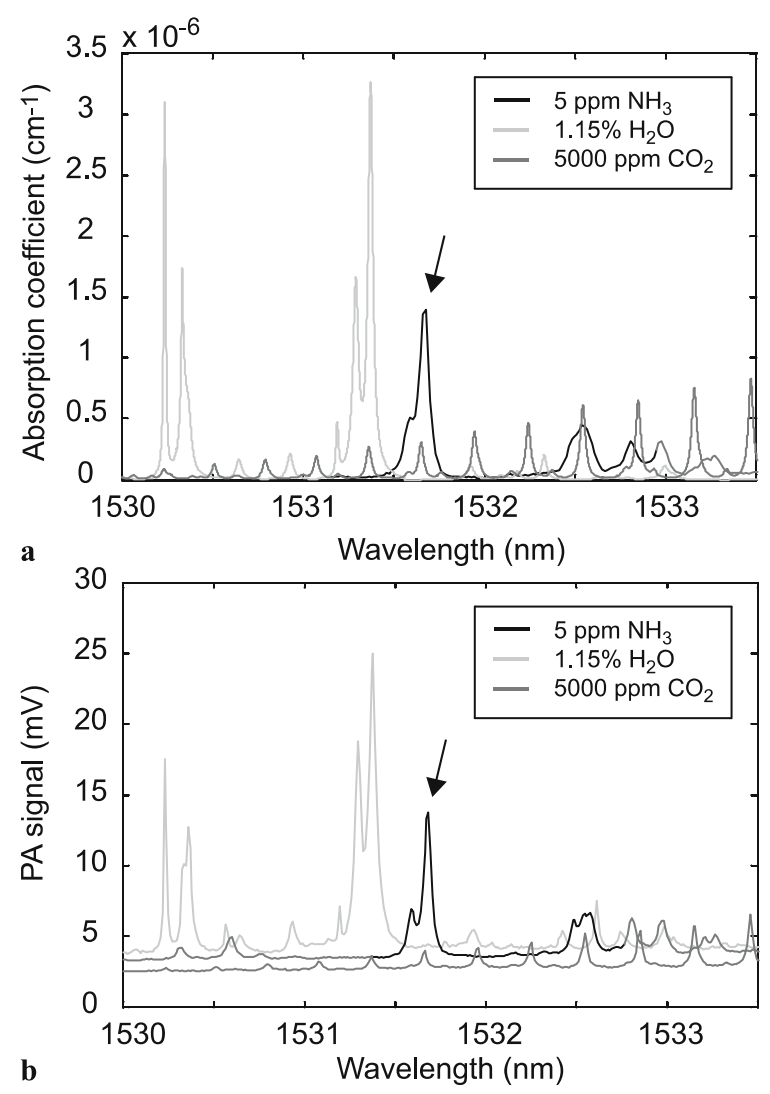

FIGURE 6 (a) $\mathrm{H}_{2} \mathrm{O}$ and $\mathrm{CO}_{2}$ spectra calculated from the HITRAN database [16] and $\mathrm{NH}_{3}$ spectrum obtained from the PNNL database [17] for concentrations of respectively $1.15 \%, 5000 \mathrm{ppm}$ and $5 \mathrm{ppm}$. (b) Corresponding PA spectra measured using the EDFA and an external chopper for the same compounds concentrations. The arrow shows the selected ammonia line used for measurements

perimental and calculated spectra. Concentrations of $1.15 \%$ of $\mathrm{H}_{2} \mathrm{O}$ (corresponding to $50 \%$ of relative humidity at $20^{\circ} \mathrm{C}$ ), $5000 \mathrm{ppm}$ of $\mathrm{CO}_{2}$ and $5 \mathrm{ppm}$ of $\mathrm{NH}_{3}$ were used to record each spectrum separately. The DFB laser diode temperature was tuned to between $5{ }^{\circ} \mathrm{C}$ and $40^{\circ} \mathrm{C}$ covering a spectral range from $1530 \mathrm{~nm}$ to $1534 \mathrm{~nm} . \mathrm{CO}_{2}$ and $\mathrm{H}_{2} \mathrm{O}$ spectra calculated from HITRAN database [16] and a FTIR $\mathrm{NH}_{3}$ spectrum obtained from the PNNL database [17] are presented in Fig. 6a. A good agreement between experimental and databases spectra is observed. The strongest $\mathrm{NH}_{3}$ absorption line is located at $1531.67 \mathrm{~nm}$ where $\mathrm{H}_{2} \mathrm{O}$ and $\mathrm{CO}_{2}$ also contribute to the PA signal. Since ammonia detection is performed using a wavelength-modulation scheme in combination with $2 f$ detection, the same scheme was applied to quantify $\mathrm{H}_{2} \mathrm{O}$ and $\mathrm{CO}_{2}$ interferences. A scan of the absorption lines of $1 \mathrm{ppm}$ $\mathrm{NH}_{3}, 4000 \mathrm{ppm} \mathrm{CO}_{2}$ and $1.9 \% \mathrm{H}_{2} \mathrm{O}$ in a balance of dry air ( $80 \%$ of $\mathrm{N}_{2}$ and $20 \%$ of $\mathrm{O}_{2}$ ) was carried out by tuning the laser current from $60 \mathrm{~mA}$ to $120 \mathrm{~mA}$, corresponding to a frequency scan of $51 \mathrm{GHz}$ (see Fig. 7). The output power of the EDFA was considered to be constant over this scan since the amplifier was used in the saturation regime. In order to determine the equivalent $\mathrm{NH}_{3}$ concentration due to the contribution of $\mathrm{CO}_{2}$ and $\mathrm{H}_{2} \mathrm{O}$, an average value of the corresponding PA signals measured at the centre of the $\mathrm{NH}_{3}$ line was determined over $5 \mathrm{~min}$ (10 s integration time). Typical $\mathrm{CO}_{2}$ and $\mathrm{H}_{2} \mathrm{O}$ concentrations present in atmosphere were considered 


\begin{tabular}{llccc}
\hline Molecule & $\begin{array}{c}\text { wavenumber } \\
\left(\mathrm{cm}^{-1}\right)\end{array}$ & $\begin{array}{c}\text { Linestrength } \\
\left(\mathrm{cm}^{-1} /\left(\mathrm{mol} \mathrm{cm}^{-2}\right)\right)\end{array}$ & $\begin{array}{c}\text { Air-broadening } \\
\text { coefficient }\left(\mathrm{cm}^{-1}\right)\end{array}$ & $\begin{array}{c}\text { Self-broadening } \\
\text { coefficient }\left(\mathrm{cm}^{-1}\right)\end{array}$ \\
\hline $\mathrm{NH}_{3}$ & 6528.76 & $2.52 \times 10^{-21}$ & 0.1 & 0.45 \\
$\mathrm{NH}_{3}$ & 6528.89 & $1.34 \times 10^{-21}$ & 0.1 & 0.45 \\
$\mathrm{CO}_{2}$ & 6528.893968 & $5.19 \times 10^{-25}$ & 0.0676 & 0.0818 \\
\hline
\end{tabular}

TABLE 2 Parameters of the strongest $\mathrm{NH}_{3}$ and $\mathrm{CO}_{2}$ lines around $1531.67 \mathrm{~nm}$ used in the simulations of the $2 f$-PA signals according to the data from Webber et al. [18] and Hitran [16]

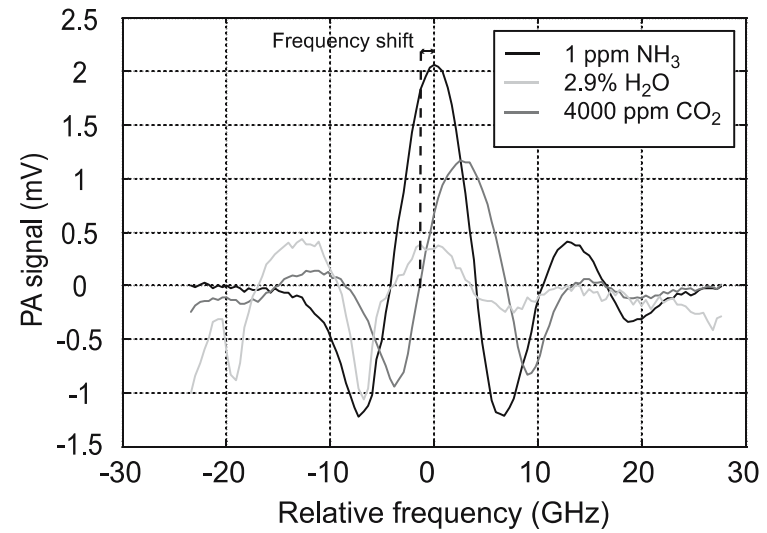

FIGURE $7 \quad \mathrm{NH}_{3}, \mathrm{CO}_{2}$ and $\mathrm{H}_{2} \mathrm{O}$ measured spectra at $2 f$. Interferences are calculated by measuring the contribution of $\mathrm{CO}_{2}$ and $\mathrm{H}_{2} \mathrm{O}$ at the centre of the ammonia feature $(0 \mathrm{GHz})$. Typical concentrations in air of $1.15 \%$ of $\mathrm{H}_{2} \mathrm{O}$ $\left(50 \%\right.$ of relative humidity at $20^{\circ} \mathrm{C}$ ) and $400 \mathrm{ppm}$ of $\mathrm{CO}_{2}$ correspond to an ammonia equivalent concentration of 36 and $100 \mathrm{ppb}$. The frequency shift represents the shift to apply on the laser dc current to obtain a 0 contribution of $\mathrm{CO}_{2}$ interference

to deduce the interference contribution. Thus, it was determined that $400 \mathrm{ppm}$ of $\mathrm{CO}_{2}$ and $1.15 \%$ (50\% of relative humidity at $20^{\circ} \mathrm{C}$ ) correspond to $36 \mathrm{ppb}$ and $100 \mathrm{ppb}$ of $\mathrm{NH}_{3}$ at $1531.67 \mathrm{~nm}$, respectively.

These interferences can be reduced by operating the system at low pressure [9], but operation at atmospheric pressure was nevertheless preferred to maintain a simple configuration. In that case, water vapour contribution can be compensated by measuring the ambient humidity with a commercially available hygrometer or spectroscopically at another wavelength of the laser. In the latter case, an appropriate choice of wavelength, where only water vapour contributes to the absorbed signal, is necessary, for instance at $\lambda=1530.94 \mathrm{~nm}$. This contribution may then be subtracted from the overall signal measured on the $\mathrm{NH}_{3}$ line at $1531.67 \mathrm{~nm}$. For $\mathrm{CO}_{2}$ interference, the same procedure may be applied with a different wavelength of $\lambda=1532.25 \mathrm{~nm}$. However, a simple and original approach may also be implemented to suppress the interference from ambient $\mathrm{CO}_{2}$. The proposed method takes advantage of the slight shift between the centre of the $\mathrm{NH}_{3}$ and $\mathrm{CO}_{2}$ absorption lines around $1531.67 \mathrm{~nm}$. The main $\mathrm{NH}_{3}$ absorption feature located at $1531.67 \mathrm{~nm}\left(6528.79 \mathrm{~cm}^{-1}\right)$ is made of two close lines that overlap at atmospheric pressure, whereas the centre of the strongest $\mathrm{CO}_{2}$ line is shifted by only $0.1 \mathrm{~cm}^{-1}$ from the $\mathrm{NH}_{3}$ feature. As a result of this shift and of the different broadening coefficients of these lines (see Table 2), the zerocrossing point in the $2 f$ signal of the $\mathrm{CO}_{2}$ line is located only $-1.19 \mathrm{GHz}\left(-0.04 \mathrm{~cm}^{-1}\right)$ away from the centre of the $\mathrm{NH}_{3}$ line in our modulation conditions. By operating the laser at this specific wavelength, the $\mathrm{CO}_{2}$ contribution to the PA signal may be efficiently reduced, while keeping a strong signal from $\mathrm{NH}_{3}$.
In order to demonstrate the efficiency of this method for the reduction of the $\mathrm{CO}_{2}$ interference, some simulations of the $2 f$-PA signals from $\mathrm{NH}_{3}$ and $\mathrm{CO}_{2}$ have been performed in similar conditions encountered in the experiment (Fig. 8). For this purpose, the $2 f$-PA signals corresponding to $1 \mathrm{ppm} \mathrm{NH}_{3}$ and $4000 \mathrm{ppm} \mathrm{CO}$ have been calculated using a theoretical model of the harmonic signals generated in WM-PAS [12]. The laser modulation amplitude has been chosen to maximise the $\mathrm{PA}$ signal for $\mathrm{NH}_{3}$ at atmospheric pressure as in the experiments, thus corresponding to a modulation index (ratio of the frequency modulation amplitude to the width of the target absorption line) $m=2.2$ for $\mathrm{NH}_{3}$. The same modulation depth has been considered for $\mathrm{CO}_{2}$, hence corresponding to a larger modulation index due to the smaller linewidth of the $\mathrm{CO}_{2}$ line. The effect of the ambient pressure on the $\mathrm{CO}_{2}$ and $\mathrm{NH}_{3}$ signals has been considered in order to demonstrate that the proposed $\mathrm{CO}_{2}$-interference reduction scheme is not pressure sensitive. It can be noticed in Fig. 8 that the $\mathrm{NH}_{3}$ signal is reduced by only $10 \%$ when the laser is slightly tuned to the zero-crossing
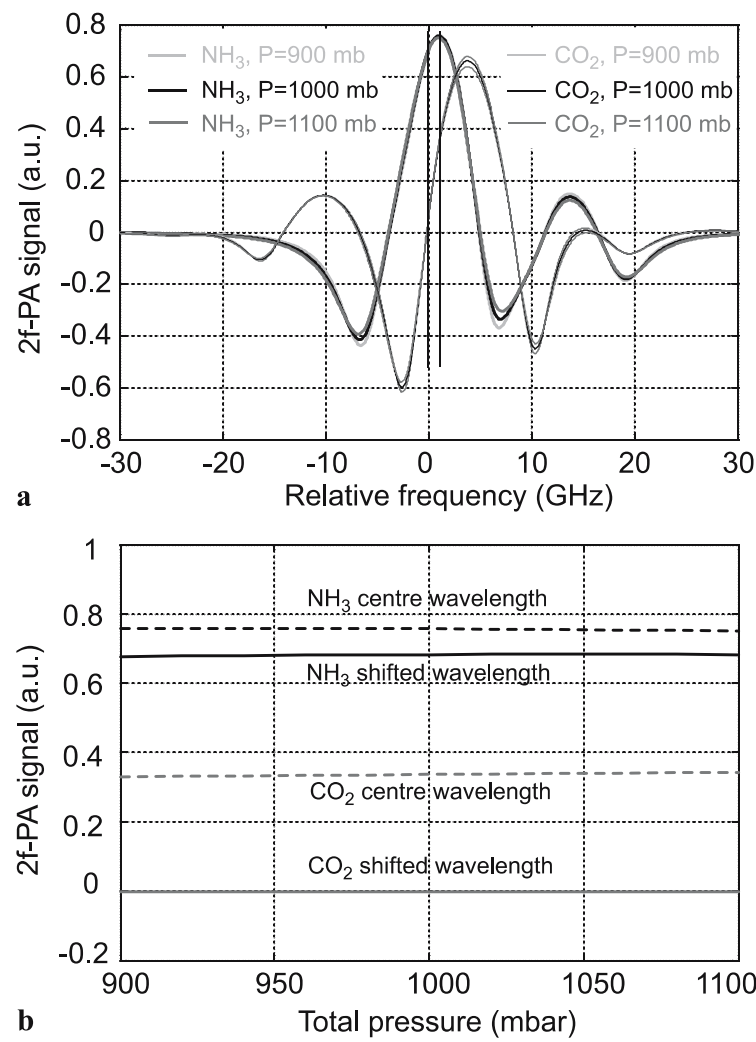

FIGURE 8 (a) Comparison of the simulated $2 f$ PA signals for $1 \mathrm{ppm} \mathrm{NH}_{3}$ and $4000 \mathrm{ppm} \mathrm{CO}_{2}$ at different pressures. The parameters of the absorption lines have been taken according to Table 2 and a modulation depth corresponding to a modulation index $m=2.2$ for $\mathrm{NH}_{3}$ at atmospheric pressure has been considered. (b) Comparison of the $\mathrm{NH}_{3}$ signal and $\mathrm{CO}_{2}$ interference obtained when the laser is tuned to the centre of the $\mathrm{NH}_{3}$ absorption feature (dashed lines) or slightly shifted $-1.19 \mathrm{GHz}$ away (solid lines) 
point of the $\mathrm{CO}_{2} 2 f$ signal compared to the maximum signal achieved at the centre of the $\mathrm{NH}_{3}$ absorption feature. At the same time, the $\mathrm{CO}_{2}$ interference is reduced by two orders of magnitude when the laser is slightly frequency shifted to this specific wavelength. The equivalent signal for $4000 \mathrm{ppm}$ of $\mathrm{CO}_{2}$ is reduced to $4 \mathrm{ppb} \mathrm{NH}_{3}$ over a pressure range of $\pm 10 \%$ around atmospheric pressure, thus corresponding to a sub$\mathrm{ppb}$ interference for a typical atmospheric concentration of $400 \mathrm{ppm} \mathrm{CO}_{2}$.

\section{Conclusion}

A PA gas sensor was developed to monitor ammonia at ppb level. Since the power of laser diodes is limited to several tens of $\mathrm{mW}$, a configuration using an optical amplifier was investigated to reach such extreme sensitivities. In addition, a well-adapted modulation scheme in combination with an optimised PA cell design are essential to achieve the best signal-to-noise ratio. A carefully designed system results in a powerful sensor capable of measuring a few ppb of ammonia. Finally, interferences from $\mathrm{H}_{2} \mathrm{O}$ and $\mathrm{CO}_{2}$ must be taken into account to measure $\mathrm{NH}_{3}$ in ambient air. An original method consisting in a wavelength shift of the laser to measure these compounds separately have been proposed to overcome this problem. The robustness of this technique over pressure variations has been validated by simulating $2 f$-PA signals from $\mathrm{NH}_{3}$ and $\mathrm{CO}_{2}$.

ACKNOWLEDGEMENTS The authors would like to acknowledge Omnisens SA for providing the reference ammonia trace gas analyser (TGA300Series).

\section{REFERENCES}

1 G. Ramis, L. Yi, G Busca, Catal. Today 28, 373 (1996)

2 S. MacDonald, N. Clecak, R. Wendt, C.G. Willson, C. Snyder, C. Knors, N. Deyoe, J. Maltabes, J. Morrow, A. McGuire, S. Holmes, Proc. SPIE 1466, 2 (1991)

3 D. Marinov, M. Sigrist, Photochem. Photobiol. Sci. 2, 774 (2003)

4 M.E. Webber, T. MacDonald, M.B. Pushkarsky, C.K.N. Patel, Y. Zhao, N. Marcillac, F.M. Mitloehner, Meas. Sci. Technol. 16, 1547 (2005)

5 L.R. Narasimhan, W. Goodman, C.K.N. Patel, Proc. Nat. Acad. Sci. 98, $4617(2001)$

6 V. Zéninari, B. Parvitte, D. Courtois, V.A. Kapitanov, Y.N. Ponomarev, Infrared Phys. Technol. 44, 253 (2003)

7 J.-P. Besson, S. Schilt, L. Thévenaz, Spectrochim. Acta A 63, 899 (2006)

8 A.A. Kosterev, F.K. Tittel, Appl. Opt. 43, 6213 (2004)

9 M.E. Webber, M. Pushkarsky, C.K.N. Patel, Appl. Opt. 42, 2119 (2003)

10 J. Henningsen, N. Melander, Appl. Opt. 36, 7037 (1997)

11 A. Schmohl, A. Miklos, P. Hess, Appl. Opt. 41, 1815 (2002)

12 S. Schilt, L. Thévenaz, Infrared Phys. Technol. 48, 154 (2006)

13 J.-P. Besson, S. Schilt, L. Thévenaz, Spectrochim. Acta A 60, 3449 (2004)

14 S. Schilt, L. Thévenaz, M. Niklès, L. Emmenegger, C. Hüglin, Spectrochim. Acta A 60, 3259 (2004)

15 C. Brand, A. Winkler, P. Hess, Miklos A., Z. Bozoki, J. Sneider, Appl. Opt. 34, 3257 (1995)

16 L.S. Rothman, D. Jacquemart, A. Barbe, D. Chris Benner, M. Birk, L.R. Brown, M.R. Carleer, C. Chackerian Jr., K. Chance, L.H. Coudert, V. Dana, V.M. Devi, J.-M. Flaud, R.R. Gamache, A. Goldman, J.-M. Hartmann, K.W. Jucks, A.G. Maki, J.-Y. Mandin, S.T. Massie, J. Orphal, A. Perrin, C.P. Rinsland, M.A.H. Smith, J. Tennyson, R.N. Tolchenov, R.A. Toth, J. Vander Auwera, P. Varanasi, G. Wagner, J. Quantum Spectrosc. Radiat. Transf. 96, 139 (2005)

17 S.W. Sharpe, T.H. Johnson, R.L. Sams, P.M. Chu, G.C. Rhoderick, P.A. Johnson, Appl. Spectrosc. 58, 1452 (2004)

18 M.E. Webber, D.S. Baer, R.K. Hanson, Appl. Opt. 40, 2031 (2001) 